Original Research Article

\title{
Nano-emulsion of methylmetacrylate / butyl acrylate crosslinked an application in acrylic emulsion paints
}

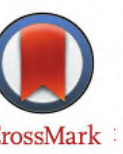

Singh, Jaspal; Chawla, Malvika; Rawat, Kavita; Singh, Om and Kaushik, R. D.

Department of Chemistry, Gurukul Kangri Vishwavidyalaya, Haridwar, Uttarakhand, India

Corresponding Author: sjs2874@yahoo.com

\section{A R T I C L E I N F O}

Received: 10 February 2018 | Accepted: 22 April 2018 | Published Online: 15 August 2018

DOI: $10.31786 / 09756272.18 .9 .1 .107$

EOI: 10.11208/essence.18.9.1.107

Article is an Open Access Publication.

This work is licensed under Attribution-Non Commercial 4.0 International

(https://creativecommons.org/licenses/by/4.0/)

CThe Authors (2018). Publishing Rights @ MANU-ICMANU \& ESSENCE-IJERC.

\section{A B S T R A C T}

This work proposes self-crosslinked nano-emulsion synthesized by emulsion polymerization of butyl acrylate (BA), methyl methacrylate (MMA), methacrylic acid (MAA) and mixed emulsifier via pre-emulsified and semi-continuous seeded emulsion polymerization technology in the presence of $\mathrm{N}$-methylolacryamide and glycedyl methyl acrylate. Emulsions used as pigment binders have to deal with the challenge to assure an outstanding film configuration and exterior as well as good mechanical properties. The influence of the mass ratio of BA to MMA, the amount of N-methylolacryamide and glycedyl methyl acrylate on the paint's properties of the self-crosslinked emulsion was examined. And the relationship between emulsion viscosity and particle size was investigated. The results show that the self crosslinked acrylate emulsion with high viscosity can be synthesized with 50:50 monomer composition of BA: MMA and added amount of $\mathrm{N}$-methylolacryamide is $0.3 \%-1.0 \%$ and added amount of solidum persulphate is $0.5 \%-1.5 \%$. The particle size of emulsion in the range of 200 to $470 \mathrm{~nm}$. The self-crosslinkage process of N-methylolacryamide involves two steps. .

\section{K E Y W O R D S}

Self-cross linkage | Acrylate nano-emulsion | Methyl methacrylate | Butyl acrylate | Condensation reaction

\section{I T A T I O N}

Singh, Jaspal; Chawla, Malvika; Rawat, Kavita; Singh, Om and Kaushik, R. D. (2018): Effect of monocrotophos on small intestine of mice. ESSENCE Int. J. Env. Rehab. Conserv. IX (1): 46-54. 


\section{Introduction}

The process of emulsion polymerization consists of dispersing a uniform emulsion in an aqueous phase with the aid of surfactants. Emulsion polymerization can also be defined as an addition polymerization process which proceeds by micellar mechanism. The polymer formed is stabilized within the emulsion by absorption onto surfactants as the polymerization proceeds. This gives polymers with high molecular weight, greater flexibility, good reproducibility, rapid reactions, high monomer conversion and low cost relative to other polymerization techniques. Compared to other heterogeneous polymerization, like suspension or precipitation, it is likely the most complicated system; all this factor make modeling of this system very difficult (Aggarwal et. al., 2007; Alexander and Napper, 1971). Acrylate emulsions manufactured by this technique are widely used in preparing emulsion paints. Acrylate emulsions are widely used owing to their good water resistance, weather resistance, ageing resistance and flexibility at low temperature (Antonietti and Landfester, 2002). They have excellent durability, which makes them suitable for indoor and outdoor decorative paints, and can be formulated into highresistance coatings for industrial uses. Selfcrosslinked acrylate emulsions can be prepared via molecular design when some functional groups are introduced into the molecular chain of a polymer (Aslamazova, 1995; Asua, 2002; Barrett, 1975).

Many studies have been carried out to analyze the effect of the nature and type of the emulsifier in emulsion polymerization. Emelie et al (Bockhorn, 1992) studied the batch emulsion copolymerization of methyl methacrylate and butyl acrylate using anionic (Sodium lauryl sulfate) and nonionic (polyethylene oxide ether) surfactants and other studied the stabilization (Candau, 1992) effect of mixed surfactant effect system in the batch polymerization of styrene, work was later continued by $\mathrm{Chu}$ and coworkers using methyl methacrylate and bytyl acrylate. Gan et al., (1993) and Candau, (1999) have carried out extensive work on micro emulsion polymerization of methyl methacrylate and other acrylate monomers, using various types of surfactant. Representative review or journal articles concerning emulsion polymerization can be found in references (Capek, 1999; Capek, 1999a; Capek, 1999b; Capek, 2001; Capek, 2002; Capek and Chern, 2001; Chern, 2002; Chern, 2003; Chu and Lin, 1992; Cunningham, 2002; El-Aasser and Miller, 1997; Emelie et. al., 1985; Gan et. al., 1993; Gao and Penlidis, 2002; Guyot, 1999; Kawaguchi, 2000; Leonardi et. al., 2005; Li and Brooks, 1992; Li-jun et. al., 2008; Moriguchi et al., 1999; Nagai, 1996; Nomura and Tobita, 2005; Poehlein and Dougherty, 1977; Snuparek, 1996; Sudol and El-Aasser, 1997; Tian-ying et. al., 2005; Tianying et. al., 2006; Ugelstad and Hansen, 1976). In this work, self-crosslinked acrylate emulsion with high elasticity was prepared via pre-emulsified and semi-continuous seeded emulsion polymerization technology by using $\mathrm{N}$ hydroxyl methyl acrylamide as self-crosslinked monomer and poly solidum maleate as protective colloid. Possible cross-linked mechanism of self-crosslinked monomer was put forward. In addition, the rheological properties of the prepared acrylate emulsion were analyzed (Vanderhoff, 1985; Wang et. al., 1994; Yan-jun et. al., 2003).

\section{Experimental}

\section{Raw materials}

Butyl acrylate (BA), methyl methacrylate (MMA) and methacrylic acid (MAA) were distilled under reduced pressure to remove the polymerization inhibitor before use. Potassium persulfate (KPS, Sigma-Aldrich) was recrystallized from water. Sodium dodecyl sulfate (SDS, Fisher), Nmethylol acrylamide (NMA, Sigma-Aldrich), hexadecane (HD, Sigma-Aldrich, 99\%), and $\mathrm{NaHCO} 3$ (E.Merk), ammonia water (E.Merk), methacrylic acid (Sigma-Aldrich), Nhydroxymethyl acrylamide (Sigma-Aldrich), poly sodium maleate were used. All the chemicals and reagents used were of analytical grade. Deionized water was used for preparation of the solutions. grade. Deionized water was used for preparation of the solutions. 


\section{Method}

Pre-Emulsification: The pre-emulsification having two components, one was a solution of the surfactant system in water and the second was a mixture of monomers in the required ratio (like 45:55:: 50:50:: 55:45:: 60:40 of MMA \& BA respectively for $50 \pm 1$ solid content) and special monomer (like AA, NMA, GMA). The solution of the surfactant system contains anionic and non-ionic surfactant. The mixture of monomers was dispersed into the solution of surfactant with high speed stirring.

Semi Continuous Emulsion Polymerization: The semi continuous emulsion polymerization was carried out in a glass reactor. The surfactant solution containing $\sim 33 \%$ anionic surfactant, buffer and other additives as required was charged into the reactor, the whole system was set up and heated to $80-850 \mathrm{C}$. The initiator dissolved in a desired quantity of de-ionized water was added just before the seed; then $40 \mathrm{~g}$ of pre-emulsion was added in reactor as a seed. After 15 min of seeding, the feed flow was started. The feed containing preemulsion was added over $150 \mathrm{~min}$ at $80 \pm 2^{\circ} \mathrm{C}$ temperature. The polymerization was continued thereafter in batch for about 1 hour, to kill unreacted monomer. After $1 \mathrm{hr}$. the reactor cooled down to $35{ }^{\circ} \mathrm{C}$ and ammonia was added drop wise for adjustment to $\mathrm{pH}$ (8-9). The emulsion was discharged from glass reactor and filtered through 200 mesh.

\section{Characterization}

The emulsion prepared was characterized for their ability to perform as a binder in paints.

1. Solid Content (\% NVM): This method is used to determine the percentage of non-voaltile material. The weighed quantity of sample was wrapped in aluminium foil and then kept in oven at $105{ }^{\circ} \mathrm{C}$ for 3 hours. The amount of solid content was determined by using following formula:

$\% N V M=(W 3-W 1) /(W 2-W 1) X 100$

Where,

$\mathrm{W} 1=$ Weight of empty aluminium foil

$\mathrm{W} 2=$ Weight of aluminium foil with sample

W3 $=$ Weight after drying sample
2. $\mathrm{pH}$ at $300{ }^{\circ} \mathrm{C}$ : A digital $\mathrm{pH}$ meter standardized against buffer solution was employed.

3. Viscosity (poise): The viscosity of the emulsion was tested by Brookfield viscometer at $300{ }^{\circ} \mathrm{C}$. Then calculated by given formula:

\section{Viscosity $=($ Recorded X Tablulated $) \div 100$}

4. Particle size (nm): The droplet sizes of unpolymerized microemulsions and the particle sizes of polymerized latexes were determined with a transmission electron microscope.

5. Freeze-thaw stability (cycle): The exact test condition may be varied to suit the condition expected to be encounted in actual use. A typical cycle involves freezing at $-15{ }^{\circ} \mathrm{C}$ for 16 hours, followed by thawing at ambient temperature. This cycle was repeated as often as required.

6. Electrolytic stability: The electrolytic stability was tested by using $10 \%$ solution of $\mathrm{CaCl}_{2}$. The equal volume of the emulsion and solution of $\mathrm{CaCl}_{2}$ was kept at room temperature for 72 hours.

7. Minimum film forming temperature: Minimum Film Forming Temperature (MFFT) is the lowest temperature at which an emulsion will uniformly coalesce when laid on a substrate as a thin film. Continuous films are obtained at a temperature near the glass transition temperature of the polymer or more precisely, above the MFFT.

8. Hardness: Hardness is defined as a resistance of a material to deformation, indentation or scratching. The test was performed using Rock well hardness. A specimen was kept on a hard, flat surface and an average of three readings was noted from different locations. Hardness is expressed by percentage of hard surface on which specimen was placed.

9. Water resistance: The water resistance of the emulsion film was measured by placing a water drop on polymer film and time was measured when films become slightly white. 
10. Tensile strength: Tensile strength is the property that a polymer posses and enable the film to withstand the maximum load acting upon the sample with a tendency to break or failure, it is expressed in $\mathrm{N} / \mathrm{m}^{2}$ calculated using the following formula:

\section{Tensile Strength $=\operatorname{Load}(\mathrm{N}) \div \operatorname{Area}\left(\mathbf{m}^{2}\right)$}

11. Percentage elongation: It is the maximum elongation, expressed as percentage of the original specimen length, that a specimen can endure before breaking. The crosshead speed for the above test were kept at $50 \mathrm{~mm} / \mathrm{min}$ in order to make comparisons.

12. Alkali resistance: The alkali resistance was tested by using $10 \%$ solution of $\mathrm{NaOH}$. The emulsion was weighed, dried and kept in alkali solution for seven days at room temperature. After seven days, the sample was washed with water and dried. The sample was then weighed and the percentage of alkali resistance was calculated.

\section{Results and Discussion}

The effect was insignificant on viscosity and electrolytic stability, however, with more BA and reducing the level of initiator the freeze thaw stability was reduced. No significant difference was observed in emulsion properties after incorporating glycedyl methacrylate and N-methyl methacrylate. The viscosity of emulsion increased with glycedyl methacrylate and $\mathrm{N}$-methyl methacrylate. By increasing the amount of anionic surfactant and nonionic surfactant emulsion viscosity increased.

As expected by increasing the amount of BA, the hardness, MFFT is reduced and elongation at maximum force is increasing. This is due to the low $\mathrm{Tg}$ of BA. By partial substitution of MMA with styrene and reducing the initiator level, water resistance and elongation at maximum force reduced of emulsion film (Graph 1). By incorporation of GMA and NMA the polymer film hardness, increased, but tensile strength and MFFT were reduced. It did not have any significant effect on polymer film properties by the addition of anionic sur- factant, but by increasing the amount of surfactant B the polymer film hardness improved (Table 1 and Table 2).

1. Effect of post addition of MMA in 55:45 (BA:MMA) monomer composition: It had an adverse effect on freeze-thaw stability. The polymer film hardness and water resistance was reduced on post addition of MMA

2. Effect of initiator level in 50:50 (BA:MMA) monomer composition: By reducing the level of the initiator, the freeze-thaw stability of the emulsion was reduced. It did not have any significant effect on emulsion viscosity. By reducing the initiator level, hardness of polymer film was improved .

3. Effect of initiator level in 55:45 (BA:MMA) monomer composition: By reducing the initiator level, the viscosity and freeze-thaw stability of the emulsion was reduced. The polymer hardness and MFFT were reduced by reducing the initiator level.

4. Effect of incorporation of glycerdyl methacrylate in 50:50 (BA:MMA) monomer composition: No significant difference was measured in emulsion properties were observed by incorporating glycedyl methacrylate. Polymer film hardness was increased, whereas MFFT was reduced.

5. Effect of incorporation of N-methylol acrylamide (NMA) in 50:50 (BA:MMA) monomer composition: By incorporation of NMA, the emulsion viscosity was increased and MFFT was reduced. Polymer film hardness increased, but the tensile strength decreased (Graph 2).

6. Effect of anionic surfactant in 50:50 (BA:MMA) monomer composition: By increasing the amount of anionic surfactant, emulsion viscosity increased. It did not have any significant effect on polymer film properties (Graph 3)

7. Effect of NMA in different monomer composition with anionic surfactant: With higher butyl acrylate content, the viscosity was decreased and MFFT was drastically reduced by the incorporation of NMA. The polymer film hardness reduced with an increase in butyl acrylate 
content.

8. Effect of acrylic acid (AA) in 50:50/5g (BA:MMA/MMA) monomer composition: By reducing the amount of acrylic acid, the viscosity of the emulsion was reduced. It did not have any significant effect on polymer film hardness and MFFT.

9. Various effect of reagent figure was not re quired.

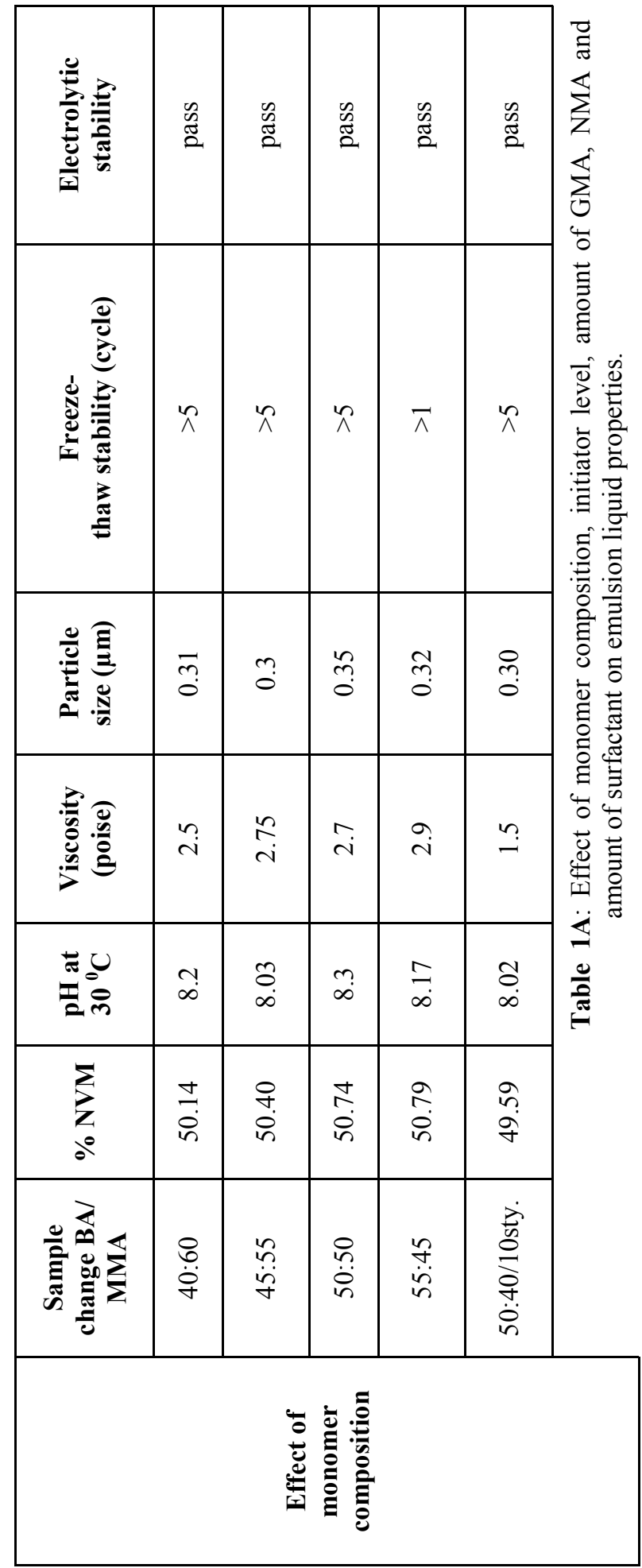

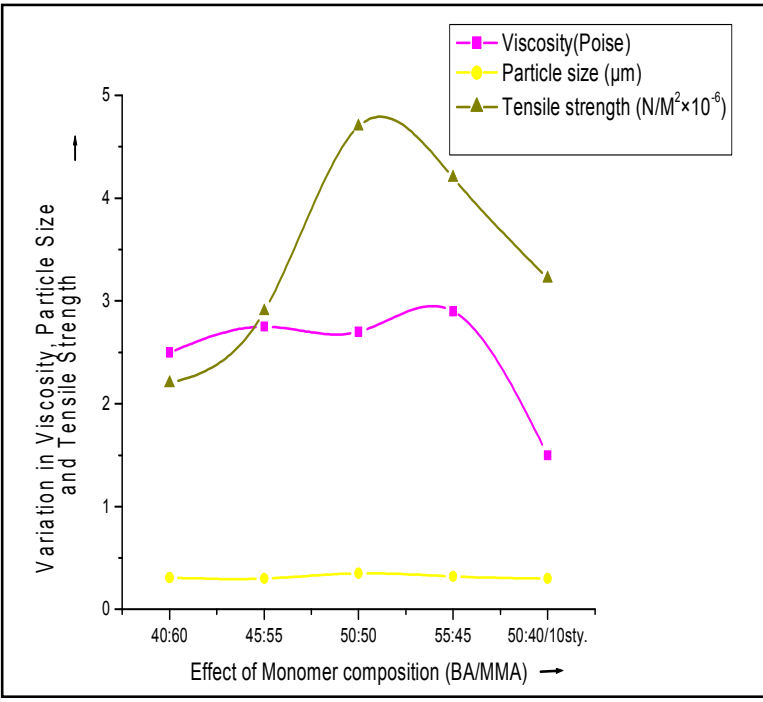

Graph 1: Effect of monomer composition (BA/ MMA) on addition of Styrene

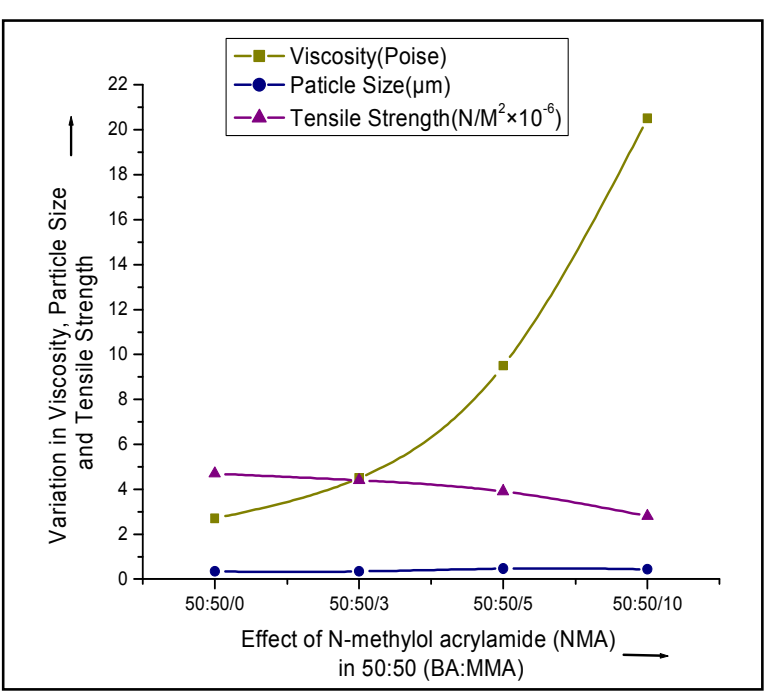

Graph 2: Effect of incorporation of N-methylol acrylamide (NMA) in 50:50 (BA:MMA) monomer composition

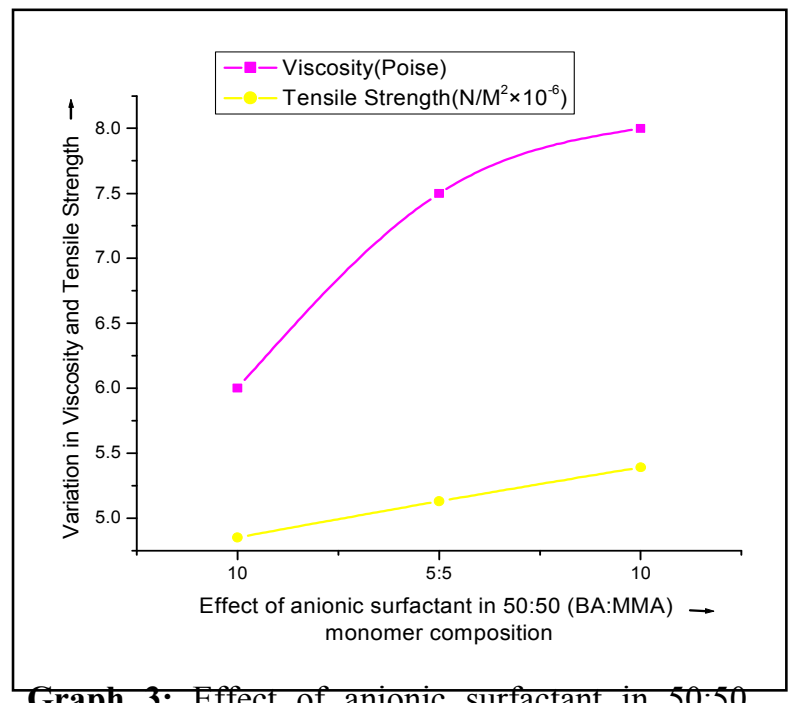

(BA:MMA) monomer composition 
ESSENCE_IJERC | Jaspal et al. (2018) | IX (1): 46-54

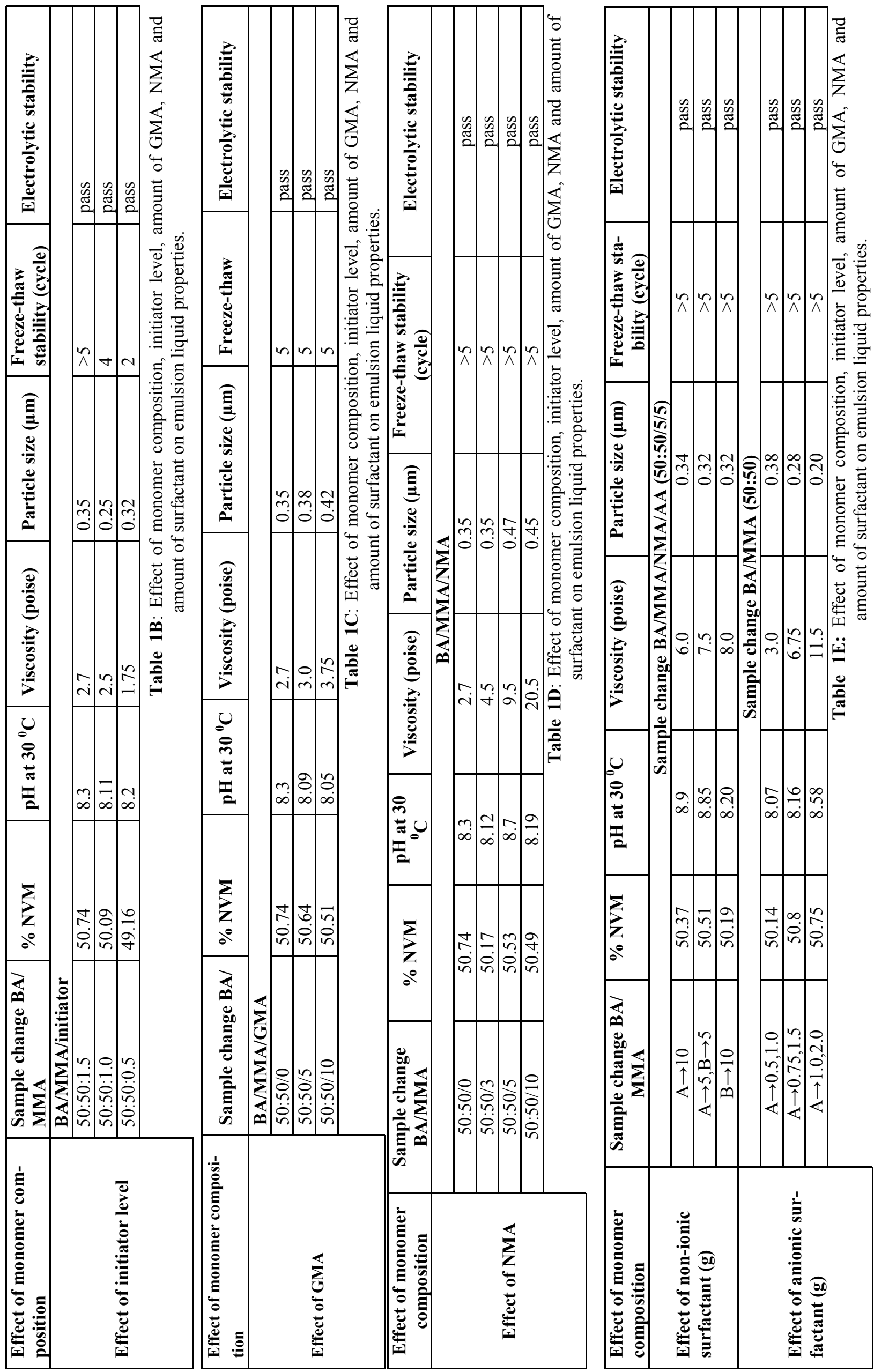


ESSENCE_-IJERC | Jaspal et al. (2018) | IX (1): 46-54
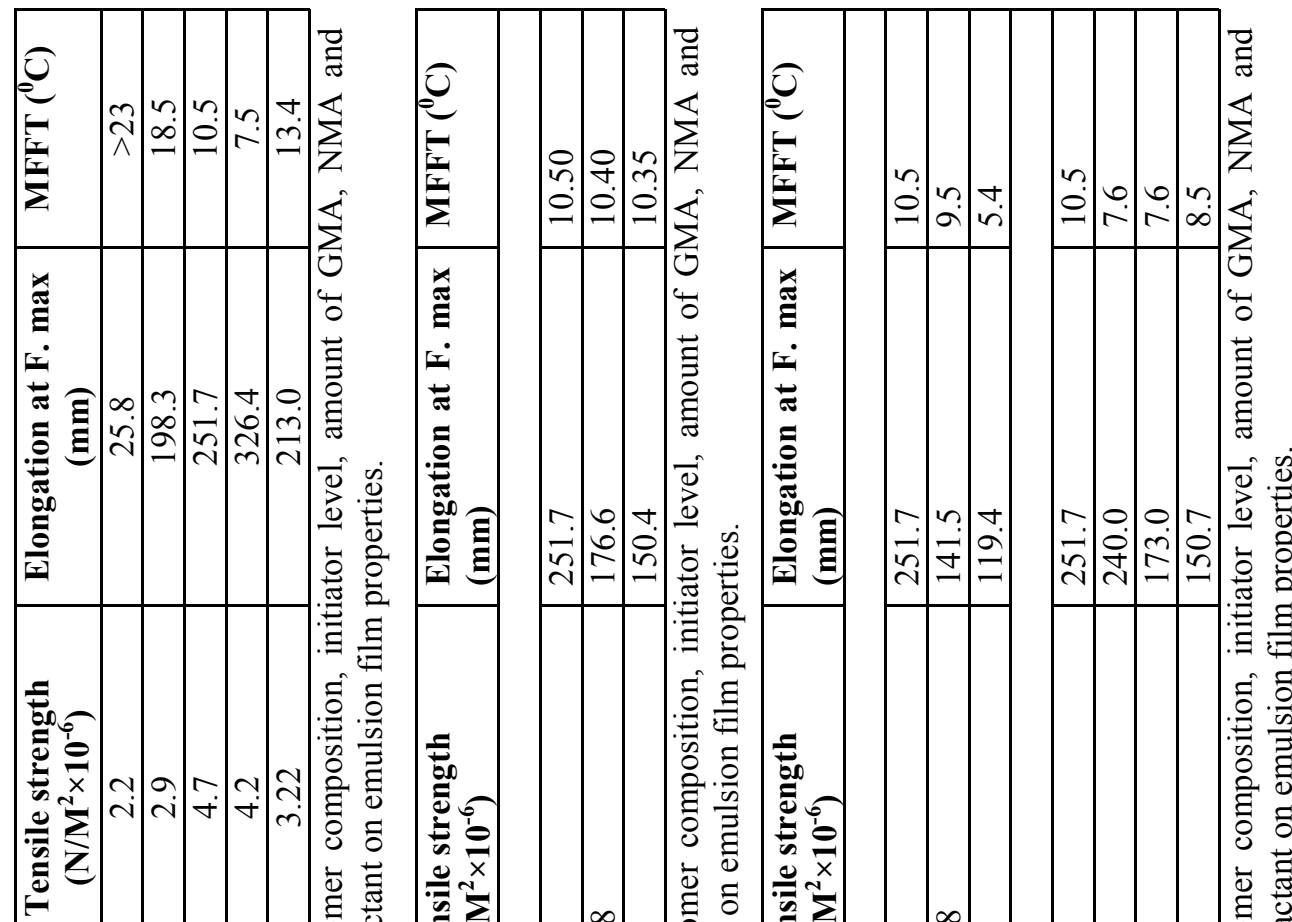

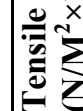

$(x)$

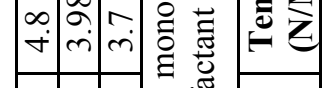

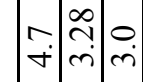

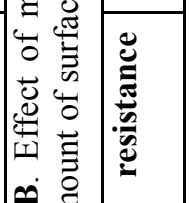

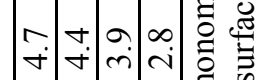

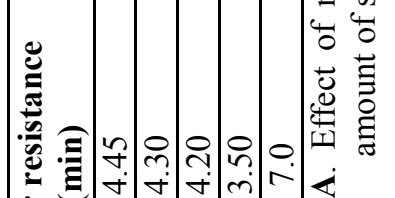

案

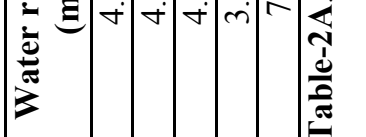

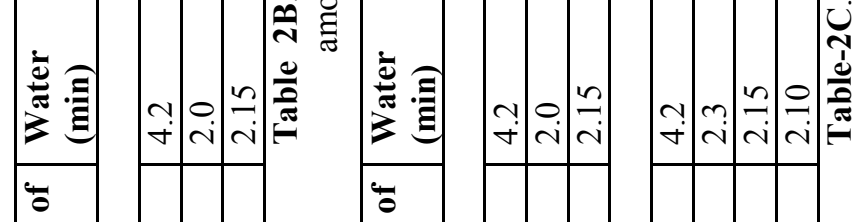

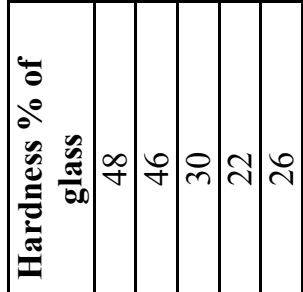

萡

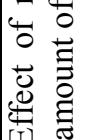

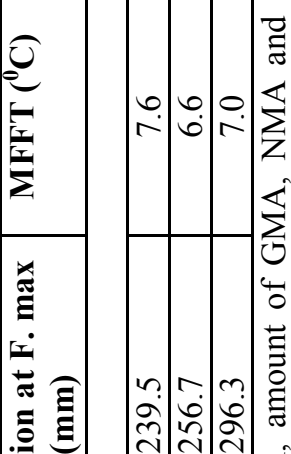

열

वे

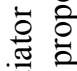

$\Xi$

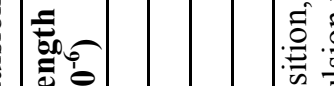

율 $\frac{0}{4}$

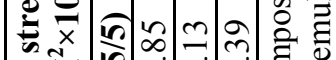

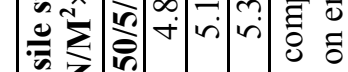

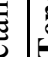
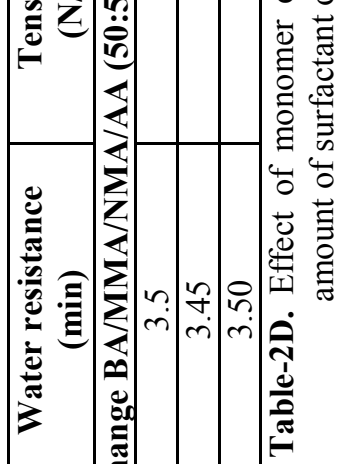

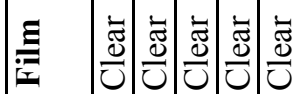

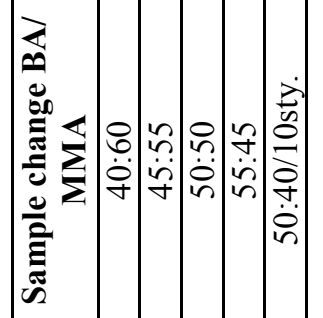

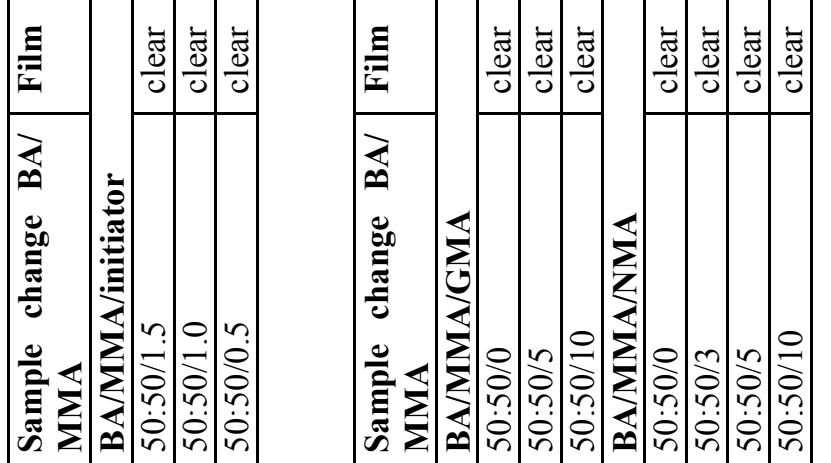

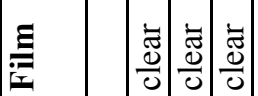
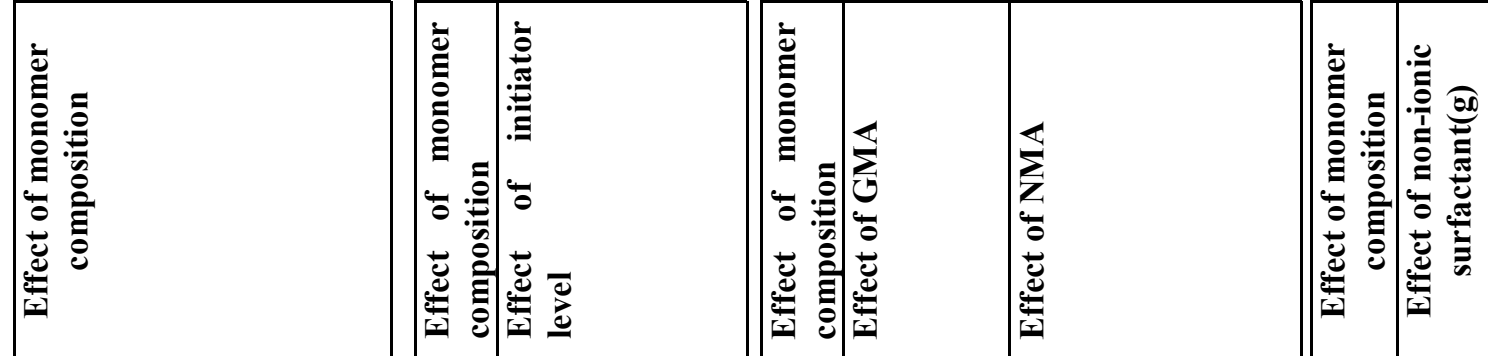


\section{Conclusion}

By this work it is clear that, the emulsion polymerization technique need soft, hard and functional monomers. It is observed that, emulsion polymerization is a type of radical polymerization that usually starts with an emulsion incorporating water, monomer, and surfactant. With increasing proportion of monomers in the formulation, lower conversion was observed which could be due to the lower reactivity of monomers for radical polymerization in the presence of these others monomers. Self-cross linked emulsion with high elasticity is prepared and the pre-emulsified and semicontinuous seeded emulsion polymerization is adopted. Possible cross-linked mechanism of self cross linked monomer involves two steps. One is copolymerization of $\mathrm{N}$-hydroxymethyl acrylamide and acrylate, the other is the cross-linkage among polymer molecule via condensation reaction of methylol. The relationship between viscosity of the emulsion and shear rate shows that the emulsion is of the rheological properties of pseudoplastic fluid.

\section{References}

Aggarwal, L. K.; Thapliyal P. C. and Karade S. R. (2007): Properties of polymer-modified mortars using epoxy and acrylic emulsions. Constr. Build. Mater., 21(2), 379-383.

Alexander, A. E. and Napper, D. H. (1971): Emulsion polymerization. In: Jensen DP, editor. Progress in polymer science. Oxford: Pergamon Press, 145-97.

Antonietti, M. and Landfester, K. (2002): Polyreactions in miniemulsions. Prog. Polym. Sci., 27, 689-757.

Aslamazova, T. R. (1995): Emulsifier-free latexes and polymers on their base. Prog. Org. Coat., 25, 109-167.

Asua, J. M. (2002): Miniemulsion polymerization. Prog. Polym. Sci., 27, 1283-346.

Barrett, K. E. (1975): Dispersion polymerization in organic media. New York: Wiley.

Bockhorn, H. (1992): Mathematical Modeling, ULLMANN'S Encyclopedia of Industrial Chemistry, B1(2).
Candau, F. (1992): Polymerization in microemulsions. In: Paleos CM, editor. Polymerization in organized media. Philadelphia: Gordon \& Breach, 215-282.

Candau, F. (1999): Polymerization in microemulsions. In: Kumar P, Mittal KL, editors. Handbook of microemulsion science and technology. New York: Marcel Dekker, 679 -712 .

Capek, I. (1999): Microemulsion polymerization of styrene in the presence of anionic emulsifier. Adv. Colloid Interface Sci., 82, 25373.

Capek, I. (1999a): Radical polymerization of polar unsaturated monomers in direct microemulsion systems. Adv. Colloid Interface Sci., 80, 85-149.

Capek, I. (1999b): Radical polymerization of polyoxyethylene macromonomers in disperse systems. Adv. Polym. Sci., 145, 1-55.

Capek, I. (2001): On the role of oil-soluble initiators in the radical polymerization of micellar systems. Adv. Colloid Interface Sci., 91, 295-334.

Capek, I. (2002): Sterically and electrosterically stabilized emulsion polymerization. Kinetics and preparation. Adv. Colloid Interface Sci., 99, 77-162.

Capek, I. and Chern, C. S. (2001): Radical polymerization in direct miniemulsion systems. Adv. Polym. Sci., 155, 101-165.

Chern, C. S. (2002): Polymerization of monomer emulsions. In: Hubbard A, editor. Encyclopedia of surface and colloid science. New York: Marcel Dekker, 4220-4241.

Chern, C. S. (2003): Microemulsion polymerization. In: Encyclopedia of polymer science and technology.

Chu, H. and Lin, C. (1992): The stabilization effect of mixed-surfactants in the emulsion polymerization of n-butyl acrylate. Polym. Bull., 28, 419.

Cunningham, M. F. (2002): Living/controlled radical polymerizations in dispersed phase systems. Prog. Polym. Sci., 27, 1039-67. 
El-Aasser, M. S. and Miller, C. M. (1997): Preparation of latexes using miniemulsions. In: Asua JM, editor. Polymeric dispersions. Principles and applications. Dordrecht: Kluwer, 109-26.

Emelie, B.; Pichot, C. and Guillot, J. (1985): Batch emulsion copolymerization of $n$ butyl acrylate and methyl methacrylate in the presence of a nonionic surfactant. Makromol. Chem. Phy., 10, 43-57.

Gan, L. M.; Chew, C. H.; Ng, S. C. and Loh, S. E. (1993): Polymerization of methyl methacrylate in ternary systems: emulsion and microemulsion. Langmuir., 9, 2799.

Gao, J. and Penlidis, A. (2002): Mathematical Modeling and Computer Simulator/ datolymerizations; Prog. Polym. Sci. 27, 403-535.

Guyot, A. (1999): Recent advances and challenges in the synthesis of polymer colloids. Colloid Surf. A: Physicochem. Eng. Aspects, $153,11-21$.

Kawaguchi, H. (2000): Functional polymer microspheres. Prog. Polym. Sci., 25, 1171-1210.

Leonardi, F.; Derail, C. and Marin, G. (2005): Some applications of molecular rheology: Polymer formulation and molecular design. J. Non-Newton. Fluid Mech., 128(1), 5061.

Li, B. and Brooks, B. W. (1992): Semi-batch processes for emulsion polymerization. Polym. Int., 29, 41-46.

Li-jun, C.; Feng-qin, W.; Dong-shuang, L.; Jian, Y. and Rong-xian, L. (2008): Preparation of self-crosslinked acrylate emulsion with high elasticity and its rheological properties. J. Cent. South Uni. Technol., 15, 324328.

Moriguchi, N.; Tsugaru, T. and Amiva, S. (1999): Molecular design of the polymer forming the complex with metal (I): Design of the hard-segments of thermoplastic elastomers by using model compounds. J. Mol. Struct., 477, 191-199.

Nagai, K. (1996): Radical polymerization and potential applications of surface-active monomers. Trends Polym Sci., 4, 122-127.
Nomura, M. and Tobita, H. (2005): Suzuki K. Emulsion polymerization: kinetic and mechanistic aspects. Adv. Polym. Sci., 175, $1-128$.

Poehlein, G.W.; Dougherty, D.J. Continuous emulsion polymerization. Rubber Chem. Technol. 1977, 50, 601-638.

Snuparek, J. (1996): Principles and limits of polymer latex tailoring. Prog. Org. Coat., 29, 225-233.

Sudol, E. D. and El-Aasser, M. S. (1997): Miniemulsion polymerization. In: Lovell PA, ElAasser MS, editors. Emulsion polymerization and emulsion polymers. Chichester: Wiley, 699-722.

Tian-ying, G.; Xi, C.; Guang-jie, H.; Mou-dao, S. and Bang-hua, Z. (2005): Preparation and properties of room temperature selfcrosslinking poly (MMA-co-BA-co-St-co -VTES) latex film. Adv. Polym. Technol., 24(4), 288-295.

Tian-ying, G.; Xi, C.; Mou-dao, S. and Bang-hua, Z. (2006): Preparation and properties of core [poly(styrene-n-butyl acrylate)]-shell [poly(styrene-methyl methacrylate-vinyl triethoxide silane)] structured latex particles with self-crosslinking characteristics. J. Appl. Polym. Sci., 100(3),1824-1830.

Ugelstad, J. and Hansen, F. K. (1976): Kinetics and mechanism of emulsion polymerization. Rubber Chem. Technol., 49, 536-609.

Vanderhoff, J. W. (1985): Mechanism of emulsion polymerization. J. Polym. Sci. Polym. Symp., 72, 161-98.

Wang, Q.; Fu, S. and Yu, T. (1994): Emulsion polymerization. Prog. Polym. Sci., 19, 703753.

Yan-jun, C.; Chao-can, Z.; Yi-feng, W.; Shi-yuan, C. and Pei-zhi, C. (2003): Study of selfcrosslinking acrylate latex containing fluorine. J. Appl. Polym. Sci., 90(13), 3609-3616. 